\title{
Real-world use of angiotensin-converting enzyme inhibitors/angiotensin receptor blockers/ $\beta$-blocks in Chinese patients before acute myocardial infarction occurs: patient characteristics and hospital follow-up
}

Xuhe Gong ${ }^{1} \mathbb{D}$, Xiaosong Ding ${ }^{1}$, Hui Chen ${ }^{1}$ and Hongwei Li $i^{1,2,3^{*}}$

\begin{abstract}
Background: Current guidelines recommend angiotensin-converting-enzyme inhibitors (ACEI) or angiotensinreceptor blockers (ARB) or $\beta$-blockers ( $\beta$-B) for secondary prevention in patients after an acute myocardial infarction (AMI). However, there is limited data to evaluate ACEI/ARB/ $\beta-B(A A B)$ used before AMI on major adverse cardiovascular events (MACE), in China patients.

Objectives: This study sought to investigate whether AA $\beta$ treatment prior to AMI is associated with better hospital outcomes at the onset of AMI.

Methods: A total of 2705 patients were selected from the Cardiovascular Center Beijing Friendship Hospital Database Bank, and divided into two groups on the basis of admission prescription: AA $\beta(n=872)$ or no-AA $\beta(n=1833)$. The study was also designed using propensity-score matching (226 AA $\beta$ treated patients vs 452 no-AA $\beta$ treated patients). The primary outcome was a composite of cardiac death and heart function and infarct size during hospitalization follow-up.
\end{abstract}

Results: The mean follow-up period was about 8 days in MACE. The Cox model showed the two groups had similar risk of cardiac death. The in-hospital mortality was 3.36\% (3.33\% of AA $\beta$ users and $3.38 \%$ of nonusers, $p=0.94$ ). In adjusted analysis, there was still no difference in in-hospital mortality between the two groups (3.54\% vs $2.88 \%$, $p=0.64)$. However, the $A A \beta$ treated patients were associated with better heart function and smaller infarct size than the no-AA $\beta$ treated patients.

Conclusions: The in-hospital MACE was similar between AA $\beta$ treated patients and no-AA $\beta$ treated patients. However, treatment with AA $\beta$ before AMI was associated with improved heart function and smaller infarct size.

Keywords: Angiotensin-converting enzyme inhibitors, Angiotensin-receptor blockers, $\beta$-Blockers, Myocardial infarction, Mortality, Major adverse cardiovascular events (MACE)

\footnotetext{
*Correspondence: Ihw19656@sina.com

${ }^{1}$ Department of Cardiology, Cardiovascular Center, Beijing Friendship Hospital, Capital Medical University, Beijing 100050, People's Republic of China

Full list of author information is available at the end of the article
} 


\section{Background}

Ischemic heart disease is one of the most frequent diseases worldwide; and cardiovascular diseases are among the leading causes of death in developed industrial countries. With the development of China's economy, the number of patients with acute myocardial infarction (AMI) increases year by year in China, and the overall mortality rate is on the rise [1]. Although interventional therapy has greatly improved the prognosis of myocardial infarction, the basic drug therapy is also essential. A large number of clinical trials have found that angiotensin-converting enzyme inhibitors (ACEIs), Angiotensin-receptor blockers (ARBs) and $\beta$-blockers $(\beta-B)$ prevented ischemic events and mortality in patients with AMI [2-4]. Thus, secondary prevention protocols including these agents are regarded to be standard therapy following an AMI, along with aspirin and statins $[5,6]$. Although there is no doubt that $A C E I / A R B / \beta$-blocker $(A A \beta)$ offer the most benefit to AMI patients, there is still uncertainty about prescribing these agents to a real population of patients before AMI occurs.

Moreover, several previous studies have documented less benefit with these agents in patients with lower-risk myocardial infarctions $[7,8]$. Was it possible to improve the prognosis by taking so many drugs before myocardial infarction occurs? This is a question. In addition, most studies have a longer follow-up time, and we only focus on events during hospitalization. Therefore, by using Cardiovascular Center Beijing Friendship Hospital Database Bank, we sought to evaluate the effectiveness of AA $\beta$ treatment in improving hospital survival. This study focused on the left ventricular functions evaluated by echocardiography, myocardial infarct size estimated by peak concentration of myocardial enzyme and the major cardiovascular events (MACE) in hospital, the MACE includes cardiac-death, target vascular reconstruction, recurrent myocardial infarction, malignant arrhythmia, cerebral infarction and cerebral hemorrhage.

\section{Methods}

\section{Study population}

The present study was based on the Cardiovascular Center Beijing Friendship Hospital Database Bank (CBD Bank). Briefly, this is a single center study. From January 2013 to October 2016, a total of 2712 consecutive patients with AMI were enrolled in this study. The local institutional review board at our hospital approved the study protocol, and this study was in accord with the Declaration of Helsinki.

\section{Inclusion and exclusion criteria}

Inclusion criteria for the present analysis were as follows: (1) consecutive patients 18 years of age or older; (2) patients diagnosed with ST-segment elevation AMI (STEMI) or non-ST-segment elevation AMI (NSTEMI). Exclusion criteria were (1) a lack of documentation of prescribed medications on admission; (2) both ARB and ACEI received; (3) infectious diseases (tuberculosis, active infective endocarditis), rheumatic disease (systemic lupus erythematosus, rheumatoid arthritis, vasculitis), hematological diseases (leukemia, lymphoma, disseminated intravascular coagulation) and neoplastic disease.

Finally, a total of 2705 patients were included in this study, the study was also designed using propensity-score matching to assemble a balanced cohort. The patient flow of the study is shown in Fig. 1.

\section{The basic characteristics data}

The hospital medical records were detailed and intact. Most of the data was extracted from the medical records including demographic data (age and sex), history of past illness (hypertension, coronary disease, diabetes, hyperlipemia and other diseases), conditions of smoking and drinking, family histories [hypertension, diabetes and coronary heart disease (CHD)] and medications (ACEI, $\mathrm{ARB}, \beta$-blocker and other) before admission. Body mass

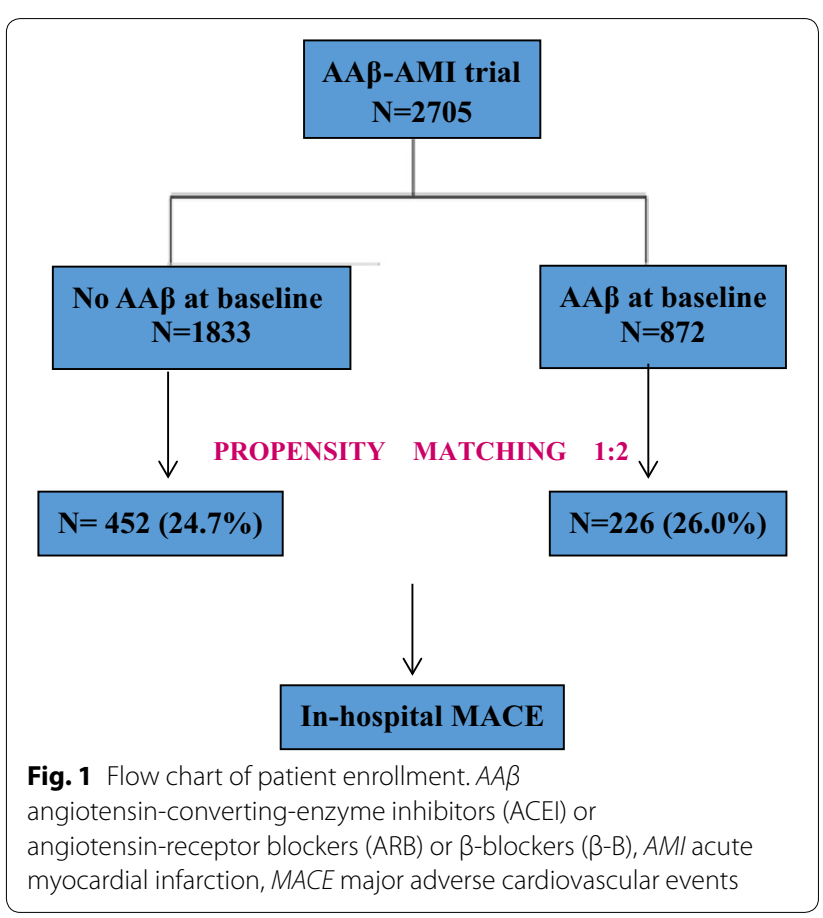


index (BMI) was calculated by dividing weight in kilograms by height in meters squared $\left(\mathrm{kg} / \mathrm{m}^{2}\right)$.

We analyzed baseline demographic characteristics, history of past illness, initial laboratory test results and medications. Blood samples for baseline laboratory tests were collected at admission or during the first 5 days after presentation of acute myocardial infarction. Serum peak concentration of cardiac troponin I (cTnI), myoglobin (Myo), creatine kinase-myocardial band (CKMB) level were used for estimation of infarct size. The LV ejection fraction was determined using 2-dimensional echocardiography during the index hospitalization. In-hospital complications and their management were also recorded.

The major adverse cardiac events (MACEs) in hospital were defined as cardiac death, target vascular reconstruction, malignant arrhythmia, recurrent myocardial infarction, cerebral infarction and cerebral hemorrhage.

\section{Data analysis}

Continuous variables are presented as mean \pm standard deviations or median with interquartile range, and were compared using the unpaired Student's t tests or the Mann-Whitney U test. Categorical variables are expressed as frequencies and percentages, and were compared by Chisquare or Fisher's extract statistics. Patients were categorized into two groups: patients receiving $\mathrm{AA} \beta$, and patients no receiving AA $\beta$. Since patients were not randomly assigned to AA $\beta$ or no-AA $\beta, 1: 2$ propensity score (PS) matching based on their probability of using AA $\beta$ was performed to reduce the effect of treatment-selection bias and potential confounding factors in this observational study. For each patient, a PS indicating the likelihood of using AA $\beta$ before hospitalization was calculated using a non-parsimonious multivariable logistic regression model with covariates including baseline demographic characteristics, such as age, sex and body mass index (BMI), past medical history including hypertension, diabetes mellitus, hyperlipidemia, heart failure, renal dysfunction and coronary heart disease.

Survival curves were conducted using Kaplan-Meier estimates and compared with the log-rank test. The multivariate Cox proportional hazards regression analysis was used to assess the association between adverse clinical events and the AA $\beta$ and no-AA $\beta$ groups. All factors showing significance in the univariate analysis $(\mathrm{p}<0.05)$ were then examined by a multivariate analysis.

All statistical tests were two-tailed, with statistical significance defined as a $\mathrm{p}$ value of $<0.05$. All analyses were performed by using SAS 9.4 (SAS Institute Inc., Cary, NC, USA) and Metaninf function in Stata 12.0.

\section{Results}

\section{Baseline characteristics \\ Overall population}

Among the 2705 eligible patients, AA $\beta$ were prescribed to 872 patients $(32.2 \%)$, and no-AA $\beta$ group was 1833 patients $(67.8 \%)$ pre-admission. The median age was 65 years (interquartile range $56-77$ years); $70.9 \%$ of the patients were men. A total of $33.9 \%$ of the patients had diabetes, $65.4 \%$ had hypertension, and just $1.29 \%$ of patients had LV systolic dysfunction. The baseline clinical characteristics are shown in Table 1.

Significant correlates of AA $\beta$ therapy in multivariable analysis are shown in Fig. 2. Compared with no AA $\beta$-treated patients, patients prescribed AA $\beta$ prior to admission were more likely to be women, and had worse baseline clinical: the higher BMI, the higher systolic and diastolic blood pressure at admission; what's more, the proportion of hypertension, diabetes, heart failure, stroke, old myocardial infarction and renal insufficiency is higher. Also, the no AA $\beta$-treated patients were more likely to have acute ST segment elevation myocardial infarction (STEMI); hence the proportion of emergency PCI (percutaneous coronary intervention) is higher.

\section{Propensity score-matched population}

Propensity scores for AA $\beta$ use, calculated for 678 patients, were used to match 226 patients receiving AA $\beta$ (33.3\%) with 452 patients no receiving AA $\beta$ (66.7\%). There were no significant differences in baseline clinical, past medical history, types of myocardial infarction between the AA $\beta$ treated and no- AA $\beta$ treated patients for the propensity score-matched subjects, except for previous PCI ( $\mathrm{p}=0.02$, Table 1$)$.

The estimated infarction size and left ventricular function between $\mathrm{AA} \beta$ treated patients and no-AA $\beta$ treated patients.

Serum peak concentration of cTnI, Myo and CKMB level were used for estimation of infarct size. We found no difference in pMyo between the two groups, however, there was higher peak level of serum myocardial enzymes ( $\mathrm{p}-\mathrm{CKMB}$ and $\mathrm{p}-\mathrm{cTnI}$ ) in the no-AA $\beta$ treated patients. (p-CKMB: 57.0 vs 31.9, $\mathrm{p}=0.02$, $\mathrm{p}$-cTnI: 6.0 vs 3.0, $\mathrm{p}=0.002$, Table 2 ).

From the perspective of cardiac function assessed by echocardiography, the AA $\beta$ treated patients were associated with better heart function and smaller infarct size than the no-AA $\beta$ treated patients. In terms of cardiac function evaluation, the left ventricular ejection fraction (EF) and fraction shortening (FS) in the AA $\beta$ treated patients were significantly higher than the no-AA $\beta$ 
Table 1 Baseline characteristics

\begin{tabular}{|c|c|c|c|c|c|c|}
\hline \multirow[t]{2}{*}{ Characteristics } & \multicolumn{2}{|l|}{ Before PS match } & \multirow[t]{2}{*}{$p$ value } & \multicolumn{2}{|l|}{ After PS match } & \multirow[t]{2}{*}{$p$ value } \\
\hline & $A A \beta(n=872)$ & NO-AA $\beta(n=1833)$ & & $A A \beta(n=226)$ & NO-AA $\beta(n=452)$ & \\
\hline \multicolumn{7}{|l|}{ Demographic } \\
\hline Age (years) & $68(58-78)$ & $63(55-76)$ & $<0.001$ & $64(55-77)$ & $66(55-78)$ & 0.56 \\
\hline Male sex & $582(66.7)$ & $1336(72.9)$ & 0.001 & $155(68.6)$ & 319 (70.6) & 0.60 \\
\hline $\mathrm{BMI}\left(\mathrm{kg} / \mathrm{m}^{2}\right)$ & $25.6(23.4-27.9)$ & $25.0(22.9-27.4)$ & 0.001 & $25.4(23.4-28.0)$ & $25.3(22.9-27.6)$ & 0.28 \\
\hline \multicolumn{7}{|l|}{ Initial presentation } \\
\hline $\mathrm{SBP}(\mathrm{mmHg})$ & $133(122-149)$ & $126(112-140)$ & $<0.001$ & $130(117-144)$ & $130(118-144)$ & 0.93 \\
\hline $\mathrm{DBP}(\mathrm{mmHg})$ & $74(67-82)$ & $72(65-80)$ & $<0.001$ & $74(67-83)$ & $74(65-82)$ & 0.50 \\
\hline Killip class $\geq 2$ & $318(36.5)$ & $531(29)$ & $<0.001$ & $65(28.8)$ & $130(28.8)$ & 0.23 \\
\hline \multicolumn{7}{|l|}{ Past history } \\
\hline HT & $836(95.9)$ & $940(51.4)$ & $<0.001$ & $191(84.5)$ & $382(84.5)$ & 1 \\
\hline DM & $376(43.1)$ & $550(30.0)$ & $<0.001$ & $29(12.8)$ & $67(14.8)$ & 0.48 \\
\hline Dyslipidemia & $414(47.6)$ & $689(38.2)$ & $<0.001$ & $78(34.5)$ & $146(32.3)$ & 0.56 \\
\hline Smoking & $460(52.8)$ & $1144(62.4)$ & $<0.001$ & $122(54.0)$ & $262(58.2)$ & 0.29 \\
\hline CRF & $96(11)$ & $101(5.5)$ & $<0.001$ & $14(6.19)$ & $23(5.09)$ & 0.55 \\
\hline $\mathrm{HF}$ & $24(2.78)$ & $11(0.61)$ & $<0.001$ & $2(0.88)$ & $2(0.44)$ & 0.48 \\
\hline$C A D$ & $459(52.7)$ & $594(32.7)$ & $<0.001$ & $35(15.5)$ & $71(15.7)$ & 0.94 \\
\hline Previous Ml & $149(17.1)$ & $172(9.5)$ & $<0.001$ & $22(9.7)$ & $35(7.8)$ & 0.38 \\
\hline Previous PCI & $219(25.1)$ & $194(10.6)$ & $<0.001$ & $18(8.0)$ & $17(3.8)$ & 0.02 \\
\hline Stroke & $188(21.6)$ & $285(15.6)$ & $<0.001$ & $41(18.1)$ & $81(17.9)$ & 0.94 \\
\hline \multicolumn{7}{|l|}{ Laboratory finding } \\
\hline $\mathrm{TC}(\mathrm{mmol} / \mathrm{L})$ & $4.10(3.44-4.78)$ & $4.42(3.77-5.08)$ & $<0.001$ & $4.27(3.61-4.86)$ & $4.42(3.84-5.04)$ & 0.01 \\
\hline TG (mmol/L) & $1.35(0.99-1.97)$ & $1.40(1.0-1.97)$ & 0.287 & $1.27(0.99-1.87)$ & $1.38(0.99-1.96)$ & 0.21 \\
\hline LDL-C (mmol/L) & $2.33(1.83-2.80)$ & $2.55(2.07-3.06)$ & $<0.001$ & $2.41(1.96-2.93)$ & $2.60(2.13-3.01)$ & 0.004 \\
\hline pNT-proBNP (ng/L) & 2035 (587-7645) & $1637(557-5475)$ & 0.01 & $1712(674-5693)$ & $1701(587-5598)$ & 0.91 \\
\hline $\operatorname{Scr}(\mu \mathrm{mol} / \mathrm{L})$ & $88.3(75.0-106.8)$ & $83.5(74.0-96.0)$ & $<0.001$ & $84.2(74.4-101.6)$ & $84.5(75.0-95.7)$ & 0.51 \\
\hline $\mathrm{GFR}(\mathrm{mL} / \mathrm{min}$ & $72.2(55.2-87.3)$ & $80.5(64.1-95.1)$ & $<0.001$ & $74.7(59.8-89.3)$ & $78.1(63.6-93.9)$ & 0.14 \\
\hline \multicolumn{7}{|l|}{ Hospital course } \\
\hline STEMI & $326(37.4)$ & $980(53.5)$ & $<0.001$ & $113(50)$ & $258(57.1)$ & 0.08 \\
\hline NSTEMI & $546(62.6)$ & $853(46.5)$ & $<0.001$ & $113(50)$ & $194(42.9)$ & 0.08 \\
\hline $\mathrm{E}-\mathrm{PCl}$ & $191(29.7)$ & $534(36.5)$ & 0.003 & $53(29.0)$ & 139 (37.6) & 0.046 \\
\hline
\end{tabular}

$A A \beta$ ACEI/ARB/ $\beta-B, B M I$ body mass index, $S B P$ systolic blood pressure, $D B P$ diastolic blood pressure, $H T$ hypertension, $D M$ diabetes mellitus, $C R F$ chronic renal failure, $H F$ heart failure, $C A D$ coronary artery disease, $M I$ myocardial infarction, $P C l$ percutaneous coronary intervention, $T C$ total cholesterol, $T G$ triglyceride, $H D L-c$ high-density lipoprotein cholesterol, LDL-c low-density lipoprotein cholesterol, NT-proBNP N-terminal pro-brain natriuretic peptide, GFR glomerular filtration rate, STEMI ST-segment elevation AMI, NSTEMI non-ST-segment elevation AMI, E-PCl emergency percutaneous coronary intervention

$p$ values for comparisons between the two groups. Significance level was 0.05

treated patients. (EF: 0.63 vs $0.61, \mathrm{p}=0.009, \mathrm{FS}: 0.34$ vs $0.33, \mathrm{p}=0.004$, Table 3$)$.

\section{Clinical outcomes}

The median follow-up duration was 8 days (interquartile range 6-10). All-cause death occurred in 91 patients $(3.4 \%)$ in the overall population. There were no significant associations between the treatment strategy and all-cause death or cardiac death. The multivariate Cox proportional hazards regression analysis showed both the $\mathrm{AA} \beta$ treated patients and no-AA $\beta$ treated patients had similar risk of cardiac death or all-cause death (cardiac death, $\mathrm{p}=0.72$, all-cause death, $\mathrm{p}=0.94$, Table 4).
After propensity-score matching, all-cause death occurred in 3.5 and $2.9 \%$ of matched patients receiving $\mathrm{AA} \beta$ and no-AA $\beta$, no significant differences were also observed in the incidence of all-cause death between the two groups.

\section{Survival}

In survival analysis, in-hospital death was no significant differences between the two groups. After adjusting for baseline clinical and propensity score, there were also no significant differences (Fig. 3). 
Characteristic

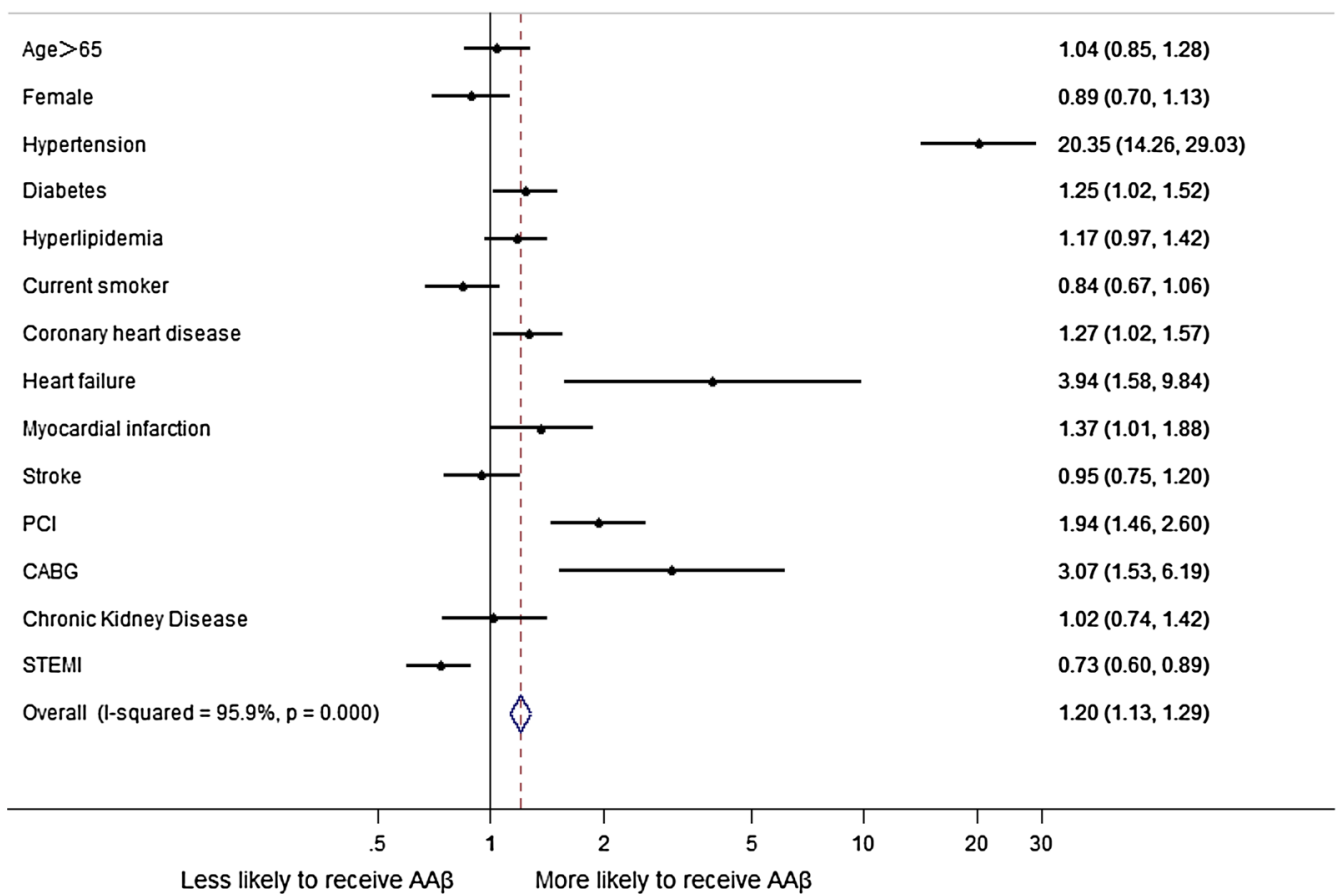

Fig. 2 Factors associated with $A A \beta$ use in multivariable analysis. Variables associated with AA $\beta$ use are shown along the vertical axis. The strength of effect is shown along the horizontal axis with the vertical line demarcating an odds ratio (OR) of 1 (i.e., no association); estimates to the right (i.e., > 1) are associated with a greater likelihood of AA $\beta$ use, whereas those to the left (i.e., <1) indicate a reduced likelihood of AA $\beta$ use. Each dot represents the point estimate of the effect of that variable in the model, whereas the line shows the $95 \%$ confidence interval (CI)

Table 2 The estimated infarction size between $A A \beta$ and NO-AA $\beta$ group

\begin{tabular}{|c|c|c|c|c|c|c|}
\hline \multirow{2}{*}{$\begin{array}{l}\text { The peak value } \\
\text { of myocardial enzyme }\end{array}$} & \multicolumn{2}{|l|}{ Before PS match } & \multirow[t]{2}{*}{$p$ value } & \multicolumn{2}{|l|}{ After PS match } & \multirow[t]{2}{*}{$p$ value } \\
\hline & $A A \beta(n=872)$ & NO-AA $\beta(n=1833)$ & & $A A \beta(n=226)$ & NO-AA $\beta(n=452)$ & \\
\hline pMyo (U/L) & $69.4(33-172)$ & 75 (32.8-228) & 0.12 & $75.2(30.1-184.5)$ & $75.9(34.8-224.5)$ & 0.32 \\
\hline $\mathrm{pCK}-\mathrm{MB}(\mathrm{ng} / \mathrm{mL})$ & $28.3(6-105)$ & $47.9(8.8-164)$ & $<0.001$ & $31.9(8.7-111)$ & $57(10-164)$ & 0.02 \\
\hline pcTnl (ng/mL) & $3.3(0.64-11.0)$ & $5.1(1.2-17.1)$ & $<0.001$ & $3.0(0.72-10.0)$ & $6.0(1.4-21.1)$ & 0.002 \\
\hline
\end{tabular}

AA $\beta$ ACEI/ARB/ $\beta-B$, Myo myoglobin, $C K-M B$ creatine kinase-myocardial band, $c T n l$ cardiac troponin I, $p$ peak value of

$p$ values for comparisons between the two groups. Significance level was 0.05

Table 3 The comparison of left ventricular function between $A A \beta$ and no-AA $\beta$ group

\begin{tabular}{|c|c|c|c|c|c|c|}
\hline \multirow[t]{2}{*}{ Characteristic } & \multicolumn{2}{|l|}{ Before PS match } & \multirow[t]{2}{*}{$p$ value } & \multicolumn{2}{|l|}{ After PS match } & \multirow[t]{2}{*}{$p$ value } \\
\hline & $A A \beta(n=872)$ & NO-AA $\beta(n=1833)$ & & $A A \beta(n=226)$ & NO-AA $\beta(n=452)$ & \\
\hline $\mathrm{LA}$ & $3.9(3.5-4.2)$ & $3.7(3.4-4.1)$ & $<0.001$ & $3.8(3.5-4.1)$ & $3.7(3.5-4.1)$ & 0.88 \\
\hline LVEDD & $5.2(4.9-5.6)$ & $5.2(4.8-5.6)$ & 0.277 & $5.2(4.8-5.5)$ & $5.2(4.8-5.6)$ & 0.20 \\
\hline $\mathrm{EF}$ & $0.61(0.53-0.67)$ & $0.61(0.52-0.66)$ & 0.029 & $0.63(0.55-0.67)$ & $0.61(0.53-0.66)$ & 0.009 \\
\hline FS & $0.33(0.27-0.37)$ & $0.33(0.27-0.36)$ & 0.016 & $0.34(0.29-0.38)$ & $0.33(0.27-0.37)$ & 0.004 \\
\hline$E / A$ & $0.82(0.69-1.17)$ & $0.87(0.72-1.24)$ & $<0.001$ & $0.88(0.70-1.20)$ & $0.84(0.70-1.19)$ & 0.37 \\
\hline
\end{tabular}

$A A \beta A C E I / A R B / \beta-B, B M I$ body mass index, $L A$ left atrium, $L V E D D$ left ventricular end-diastolic dimension, $E F$ left ventricular ejection fraction, $F S$ fraction shortening, $E / A$ ratio of early to late ventricular filling velocities

$p$ values for comparisons between the two groups. Significance level was 0.05 


\begin{tabular}{|c|c|c|c|}
\hline & $\operatorname{AA} \beta(n, \%)$ & NO-AA $\beta(n, \%)$ & $p$ value \\
\hline \multicolumn{4}{|l|}{ Overall population } \\
\hline Number & 872 & 1833 & \\
\hline MACE & $69(7.92)$ & $108(5.92)$ & 0.049 \\
\hline Cardiac-death & $28(3.21)$ & $54(2.96)$ & 0.720 \\
\hline All-cause death & $29(3.3)$ & $62(3.4)$ & 0.939 \\
\hline Target vascular reconstruction & $1(0.11)$ & $0(0)$ & 0.148 \\
\hline $\begin{array}{l}\text { Recurrent myocardial infarc- } \\
\text { tion }\end{array}$ & $39(4.48)$ & $45(2.47)$ & 0.005 \\
\hline Malignant arrhythmia & $2(0.23)$ & $2(0.11)$ & 0.451 \\
\hline Cerebral infarction & $3(0.35)$ & $7(0.39)$ & 0.874 \\
\hline Cerebral hemorrhage & $3(0.35)$ & $8(0.44)$ & 0.718 \\
\hline \multicolumn{4}{|l|}{ Matched population } \\
\hline Number & 226 & 452 & \\
\hline MACE & $13(5.75)$ & $21(4.65)$ & 0.53 \\
\hline Cardiac-death & $8(3.54)$ & $12(2.65)$ & 0.631 \\
\hline All-cause death & $8(3.54)$ & $13(2.88)$ & 0.638 \\
\hline Target vascular reconstruction & $0(0)$ & $0(0)$ & \\
\hline $\begin{array}{l}\text { Recurrent myocardial infarc- } \\
\text { tion }\end{array}$ & $6(2.65)$ & $7(1.55)$ & 0.322 \\
\hline Malignant arrhythmia & $1(0.44)$ & $2(0.44)$ & 0.999 \\
\hline Cerebral infarction & $0(0)$ & $3(0.67)$ & 0.220 \\
\hline Cerebral hemorrhage & $0(0)$ & $4(0.89)$ & 0.157 \\
\hline
\end{tabular}

$\mathrm{MACE}=$ cardiac-death or target vascular reconstruction or recurrent myocardial infarction or malignant arrhythmia or cerebral infarction or cerebral hemorrhage MACE major adverse cardiovascular events

\section{Discussion}

In this single center observational study, we found that previous treatment with $A A \beta$ was associated with a nonsignificant reduction in the risk of all-cause mortality during hospitalization. However, previous use of AA $\beta$ reduced myocardial infarction size and improved heart function.

The clinical benefit of AA $\beta$ in patients after AMI may be partly mediated by a reduction in the risk of recurrent ischemic events and reduction in congestive heart failure $[9,10]$, some studies emphasizing that the AA $\beta$ have an additive effect, which have long been reflected in the clinical guidelines, which recommend routine use of AA $\beta$ in all AMI patients [11, 12]. However, Could the drugs used in the past improve the condition of myocardial infarction? Moreover, it is controversial whether this medical prevention improves clinical outcomes in hospital. Therefore, the adherence to these guideline-based medications differs substantially among cardiovascular societies $[13,14]$. Thus, considering the potential adverse events attributed to over-use of AA $\beta$ treatment prior to AMI, treatment of the unselected population with these agents might be inappropriate in the modern PCI

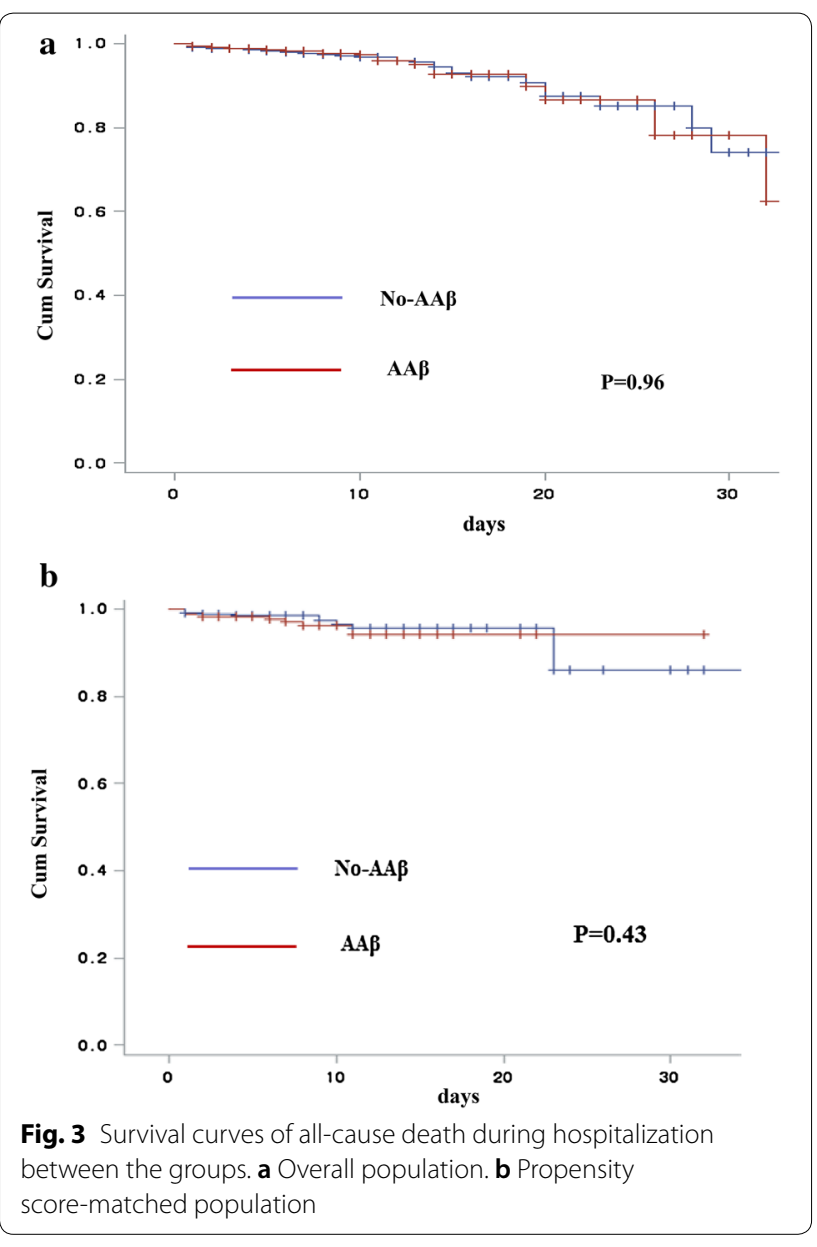

era [15]. Our current study, based on reliable data that included all AMI patient from 2013 to 2016, may provide an important "real world" insight into this debatable issue.

In our study population, $11.9 \%$ of patients had a history of myocardial infarction; we found that $53.6 \%$ of patients with old myocardial infarction were not taking the AA $\beta$, which suggests that application of medicine for improving prognosis of myocardial infarction was still inadequate. A recent clinical research conducted by Liu et al. [16] that focused on the use and trends of ACEI/ ARB therapy in China over the past decade (2001-2011), after analyzing 102,003 patients, they found that onethird of Chinese AMI patients with Class I indications do not receive ACEI/ARB therapy during hospitalization, with little improvement in rates over time. The underutilization of ACEI/ARB therapy was also observed in our study. Moreover, the main characteristics of patients who are more willing to take $\mathrm{AA} \beta$ are as follows: the history of hypertension, coronary heart disease and heart failure.

In our present analysis, the all cause death was no significant difference in patients who were treated with 
either AA $\beta$ or not before AMI occurs. After matching, there was also no difference in mortality between the two groups. This finding may be partly explained by the short follow-up time, we only observed the deaths in the hospital. If we extend the follow-up period, for example, such as 1 year, 2 years, or longer, there may be a benefit of AA $\beta$ treatment.

Moreover, could the AA $\beta$ improve the MACE? This research found that the treatment strategy was not related to target vascular reconstruction, malignant arrhythmia, cerebral infarction and cerebral hemorrhage. The only difference was the proportion of recurrent myocardial infarction, which was reduced in the no-AA $\beta$ treated patients $(2.47 \%$ vs $4.48 \%, \mathrm{p}=0.005)$; However, this difference disappears after matching. Therefore, the AA $\beta$ did not improve the in-hospital MACE. Similarly, as the follow-up time increases, the role of AA $\beta$ therapy in improving MACE may be apparent.

Although the hospital mortality was no difference between the two groups, the use of AA $\beta$ really reduced the size of the infarct area and improved heart function; In other words, the drugs used in the past improved the condition of myocardial infarction. The serum peak concentration of Myo, cTnI, CKMB level was used for estimation of infarct size [17]. We found no difference in the peak value of Myo between the two groups of patients, the peak value of CK-MB and cTnI were reduced in the $\mathrm{AA} \beta$ treated patients. We analyzed that the reasons for no difference in the peak value of Myo between the two groups are as follows: first, Myo has no myocardial specificity, and it is rapidly released into the bloodstream during myocardial infarction, with high sensitivity but poor specificity. Second, Myo increased after 1-4 h of myocardial infarction and reached peak value in 6-7 h; however, some patients see a doctor after $6-7 \mathrm{~h}$ of myocardial infarction. The detected peak value of Myo is not the true peak value of Myo during the evolution of myocardial infarction. In any case, the peak value of CK-MB and cTnI were sufficient to represent the myocardial infarct size. The size of the infarct area was indeed reduced in the AA $\beta$ treated patients.

In terms of the type of myocardial infarction, the prematch analysis showed that the proportion of STEMI in the no-AA $\beta$ treated patients was higher; therefore, it has more emergency PCI proportion. This finding may be partly explained by the characteristics of the AA $\beta$ treated patients because they had a more serious medical history, such as heart failure, stroke and coronary heart disease. As we are known, STEMI was transmural infarction with complete occlusion of the coronary arteries from a pathological point of view, this condition was often worse [18]. The use of AA $\beta$ reduces the incidence of STEMI. However, after adjusting for possible confounding variables, the benefits of $\mathrm{AA} \beta$ disappeared, there was no difference in the type of myocardial infarction between the two groups.

\section{Limitations}

Our present study had limitations inherent to its nonrandomized, observational design. First, similar to previous studies using an administrative database; we did not have full information on the dose and duration of AA $\beta$ use. Second, because china population was exclusively included in our study, it is uncertain whether these findings can be applied to other ethnic groups or research institute with different patient characteristics and procedural strategies [19]. Third, the follow-up time was still short, and there was no difference in in-hospital mortality, however, the drugs used in the past really improved the condition of myocardial infarction, which could not negate the long-term effect of the AA $\beta$. Long term follow-up needs to be continued to illustrate the real-world results.

\section{Conclusions}

In summary, the use of $A A \beta$ prior to myocardial infarction did not improve the in-hospital MACE; this may be the result of a short follow-up. However, AA $\beta$ did improve the cardiac function and reduced the infarct size. With the increase in follow-up time, we firmly believe that there must be showing the more benefits of medication and ultimately improving the MACE, These results should be confirmed by future dedicated large, randomized clinical trials with a long term follow-up.

\section{Abbreviations \\ ACEl: angiotensin-converting-enzyme inhibitors; $A R B$ : angiotensin-receptor blockers; $\beta$-B: $\beta$-blockers; AA $\beta$ : ACEI/ARB/ $\beta$-B; AMl: acute myocardial infarction; CHD: coronary heart disease; Myo: myoglobin; CK-MB: creatine kinase-myocar- dial band; cTnl: cardiac troponin I; EF: ejection fraction; FS: fraction shortening; MACE: major adverse cardiovascular events; CBD Bank: Cardiovascular Center Beijing Friendship Hospital Database Bank; STEMI: ST-segment elevation AMI; NSTEMI: non-ST-segment elevation AMI; BMI: body mass index; PCI: percutane- ous coronary intervention.}

\section{Authors' contributions}

$\mathrm{LH}$ and $\mathrm{CH}$ designed the protocol, DX participated in the clinical data collection, GX drafted the manuscript. All authors read and approved the final manuscript.

\section{Author details}

1 Department of Cardiology, Cardiovascular Center, Beijing Friendship Hospital, Capital Medical University, Beijing 100050, People's Republic of China. ${ }^{2}$ Department of Internal Medicine, Medical Health Center, Beijing Friendship Hospital, Capital Medical University, Beijing 100050, People's Republic of China. ${ }^{3}$ Beijing Key Laboratory of Metabolic Disorder Related Cardiovascular Disease, Beijing 100069, People's Republic of China.

\section{Acknowledgements}

We thank Zhao Guoliang for data collection. 


\section{Competing interests}

The authors declare that they have no competing interests.

\section{Availability of data and materials}

The data and materials can be found from the first author and corresponding author.

\section{Consent for publication}

Consent to publish from the participant to report individual patient data: not applicable (no patient identifier or personalized data shown).

\section{Ethics approval and consent to participate}

This study was approved by the Institutional Review Board of Beijing Friendship Hospital. All procedures performed in studies involving human participants were in accordance with the ethical standards of the institutional and with the 1964 Helsinki declaration and its later amendments or comparable ethical standards.

\section{Funding}

This study was supported by National Natural Science Foundation of China (Grant No. 81600196).

\section{Publisher's Note}

Springer Nature remains neutral with regard to jurisdictional claims in published maps and institutional affiliations.

Received: 15 May 2018 Accepted: 4 December 2018

Published online: 10 December 2018

\section{References}

1. Weiwei C, Runlin G, Lisheng L, et al. Outline of Chinese cardiovascular disease report 2016. Chin J Circ. 2017;32:521-9.

2. Dargie HJ. Effect of carvedilol on outcome after myocardial infarction in patients with left-ventricular dysfunction: the CAPRICORN randomised trial. Lancet. 2001;357:1385-90.

3. Hjalmarson A, Elmfeldt D, Herlitz J, et al. Effect on mortality of metoprolol in acute myocardial infarction: a double-blind randomised trial. Lancet. 1981;2:823-7.

4. Kober L, Torp-Pedersen C, Carlsen JE, et al. A clinical trial of the angiotensin-converting-enzyme inhibitor trandolapril in patients with left ventricular dysfunction after myocardial infarction. Trandolapril Cardiac Evaluation (TRACE) Study Group. N Engl J Med. 1995;333:1670-6.

5. O'Gara PT, Kushner FG, Ascheim DD, et al. 2013 ACCF/AHA guideline for the management of ST-elevation myocardial infarction: executive summary: a report of the American college of cardiology foundation/ American heart association task force on practice guidelines. Circulation. 2013;127:529-55

6. Amsterdam EA, Wenger NK, Brindis RG, et al. 2014 AHA/ACC guideline for the management of patients with non-ST-elevation acute coronary syndromes: a report of the American college of cardiology/American heart association task force on practice guidelines. J Am Coll Cardiol. 2014;64:e139-228.
7. Flather MD, Yusuf S, Kober L, et al. Long-term ACE-inhibitor therapy in patients with heart failure or left-ventricular dysfunction: a systematic overview of data from individual patients. ACE-inhibitor myocardial infarction collaborative group. Lancet. 2000;355:1575-81.

8. Kernis SJ, Harjai KJ, Stone GW, et al. Does beta-blocker therapy improve clinical outcomes of acute myocardial infarction after successful primary angioplasty? J Am Coll Cardiol. 2004;43:1773-9.

9. Kaski JC, Fernandez-Berges D. Secondary prevention after acute myocardial infarction and coronary revascularisation: focus on angiotensin converting enzyme inhibitors. Cardiovasc Drugs Ther. 2008;22:185-91.

10. Gheorghiade M, Goldstein S. Beta-blockers in the post-myocardial infarction patient. Circulation. 2002;106:394-8.

11. Perk J, De Backer G, Gohlke H, et al. European guidelines on cardiovascular disease prevention in clinical practice (version 2012). The fifth joint task force of the European society of cardiology and other societies on cardiovascular disease prevention in clinical practice (constituted by representatives of nine societies and by invited experts). Eur Heart J. 2012;33:1635-701.

12. Indications for ACE inhibitors in the early treatment of acute myocardial infarction: systematic overview of individual data from 100,000 patients in randomized trials. ACE inhibitor myocardial infarction collaborative group. Circulation. 1998;97:2202-12.

13. Kotseva K, Wood D, De Backer G, De Bacquer D. Use and effects of cardiac rehabilitation in patients with coronary heart disease: results from the EUROASPIRE III survey. Eur J Prev Cardiol. 2013;20:817-26.

14. Bauer T, Gitt AK, Junger C, et al. Guideline-recommended secondary prevention drug therapy after acute myocardial infarction: predictors and outcomes of nonadherence. Eur J Cardiovasc Prev Rehabilit. 2010;17:576-81.

15. Lee PH, Park GM, Kim YH, et al. Effect of Beta blockers and renin-angiotensin system inhibitors on survival in patients with acute myocardial infarction undergoing percutaneous coronary intervention. Medicine. 2016;95:e2971.

16. Liu J, Masoudi FA, Spertus JA, et al. Patterns of use of angiotensinconverting enzyme inhibitors, angiotensin receptor blockers among patients with acute myocardial infarction in China from 2001 to 2011: China PEACE-retrospective AMI study. J Am Heart Assoc. 2015. https:// doi.org/10.1161/JAHA.114.001343.

17. Dohi T, Maehara A, Brener SJ, et al. Utility of peak creatine kinase-MB measurements in predicting myocardial infarct size, left ventricular dysfunction, and outcome after first anterior wall acute myocardial infarction (from the INFUSE-AMI trial). Am J Cardiol. 2015;115:563-70.

18. ISIS-2 (Second International Study of Infarct Survival) Collaborative Group Randomised trial of intravenous streptokinase, oral aspirin, both, or neither among 17,187 cases of suspected acute myocardial infarction: ISIS-2. Lancet. 1988;2:349-60.

19. Yeh RW, Sidney S, Chandra M, Sorel M, Selby JV, Go AS. Population trends in the incidence and outcomes of acute myocardial infarction. N Engl J Med. 2010:362:2155-65.

Ready to submit your research? Choose BMC and benefit from

- fast, convenient online submission

- thorough peer review by experienced researchers in your field

- rapid publication on acceptance

- support for research data, including large and complex data types

- gold Open Access which fosters wider collaboration and increased citations

- maximum visibility for your research: over 100M website views per year

At $\mathrm{BMC}$, research is always in progress.

Learn more biomedcentral.com/submissions 